\title{
Sense of Coherence and Personality Traits Related to Depressive State
}

\author{
Yoko Kikuchi, ${ }^{1}$ Makoto Nakaya, ${ }^{1,2}$ Miki Ikeda, ${ }^{1}$ Shoko Okuzumi, ${ }^{1}$ \\ Mihoko Takeda, ${ }^{1}$ and Miyoko Nishi ${ }^{3}$ \\ ${ }^{1}$ Department of Psychiatry, Musashino Red Cross Hospital, Kyounancho 1-26-1, Musashino, Tokyo 180-8610, Japan \\ ${ }^{2}$ Faculty of Medicine, Tokyo Medical and Dental University, Yushima 1-5-45, Bunkyouku, Tokyo 113-8570, Japan \\ ${ }^{3}$ Department of Nurse, Musashino Red Cross Hospital, Kyounancho 1-26-1, Musashino, Tokyo 180-8610, Japan
}

Correspondence should be addressed to Yoko Kikuchi; shinnai@musashino.jrc.or.jp

Received 7 July 2014; Revised 28 August 2014; Accepted 1 September 2014; Published 9 October 2014

Academic Editor: Nicola Magnavita

Copyright (C) 2014 Yoko Kikuchi et al. This is an open access article distributed under the Creative Commons Attribution License, which permits unrestricted use, distribution, and reproduction in any medium, provided the original work is properly cited.

\begin{abstract}
Aims. The current study aims to examine the influence of job stress, SOC, and personality traits on depressive state. Methods. A selfreported survey was conducted among 347 female nurses in a general hospital. Job stress was measured using the Japanese version of the Brief-Job Stress Questionnaire scale. Depressive state was assessed by the K6 scale. We used 13-item SOC scale. Personality traits were assessed by the Japanese version of Ten-Item Personality Inventory. Multiple liner regression analyses were conducted to examine predictors that significantly affect depressive state. Results. Job and life satisfaction and SOC negatively related to the depressive state $(\beta=-0.76, P<0.01 ; \beta=-0.18, P<0.001$, resp. $)$ while neuroticism was positively correlated $(\beta=0.49, P<0.001)$. Also, intrinsic rewards tended to negatively relate $(\beta=-0.80, P<0.1)$. Conclusions. From a practical perspective, the possible influence of SOC and neurotic personality on depressive state should be considered for health care professionals.
\end{abstract}

\section{Introduction}

Job stress and personality traits are known to be significant determinants of depressive state. Previous studies found that, in hospital staff members, job stress may adversely affect mental health and lead to depressive symptoms [18]. In female nurses at a general hospital, our group found a significant relationship between depressive state and job stress measured by the effort-reward imbalance model [6]. A meta-analytic review of Stansfeld [9] suggested that job stresses were prospective risk factors for depressive and anxiety disorder. Personality aspects were suggested to play an important role for medical symptoms, work satisfaction, and work stress. Bienvenu et al. [10] investigated the relationship between personality aspects and depressive state in subjects examined by psychiatrists with the Schedules for Clinical Assessment and the Revised NEO Personality Inventory; they showed that depressive and anxiety disorders were associated with high neuroticism. We also previously investigated the relationship between job stress and temperaments in female nurses and suggested that nurses with depressive or anxious temperaments should be identified and monitored for signs of job stress [11].

One measurement that is inversely correlated with depressive state is the sense of coherence (SOC), proposed by Antonovsky [12]. SOC is based on the salutogenic model of health $[13,14]$ and is composed of three factors: comprehensibility, manageability, and meaningfulness. The comprehensibility factor suggests that stimuli deriving from internal and external environments are structured, predictable, and explicable, while manageability assesses whether resources are available to meet the demands posed by these stimuli. The third factor, meaningfulness, indicates if such demands are challenges, worthy of investment and engagement. The SOC is a personality dimension hypothesized to influence stress recognition style, to facilitate stress management, and to contribute to overall well-being. Previous studies suggested that the SOC modified the effect of job stress on mental health [15-20] and that a weak SOC was a strong predictor of mental distress including depressive state $[16,17,19,20]$. Both 
personality traits and SOC are thought to influence the effects of job stress on depressive state, but the nature and relative strength of these relationships have not been established. The aim of the current study is to examine the influences of job stress, SOC, and personality traits on depressive state.

\section{Materials and Methods}

Study subjects consisted of nurses $(n=740)$ at a general hospital with 611 beds in an urban area of Japan. Specialties of the nurses included intensive care, pediatrics, surgery, oncology, and emergency medicine. The questionnaire was distributed to subjects by their supervisors in December 2013. Management allowed the nurses to complete the questionnaires during their shifts. An explanation of the nature of the survey accompanied the questionnaire, which was anonymous and voluntary. Consent was assumed if participants answered the questionnaire. The study was approved by both the general hospital's board of directors and its Committee for the Prevention of Physical Disease and Mental Illness among Health Care Workers.

The questionnaire collected data on age, job rank (manager, middle manager, or staff nurse), hours of work (full time or part time), shift work, and overtime. Overtime was reported in hours per week. Overtime was voluntary but limited to 45 hours per month. Shift work categories included "no shift work," "shift work with night shift rotations," or "shift work without night shift rotations." Only managers have a choice in shift assignment.

We measured job stress using the Japanese version of the Brief-Job Stress Questionnaire (BJSQ), with three subscales: job stressors (17 items), stress responses (29 items), and social supports as buffering factors (9 items). The BJSQ also measured job satisfaction and life satisfaction. The questionnaire contains 57 items with four-point Likert-type responses (from "agree" $=4$ to "disagree" = 1). It has been used widely established as a method for assessing job stress in Japan and validated and tested for reliability [21].

The SOC scale consisted of 13 items assessing comprehensibility, manageability, and meaningfulness. Each item was scored with Likert-type responses from 1 to 7 points; the total of item scores was calculated as the SOC score. Higher scores indicate stronger SOC. The scale has been validated and tested for reliability [22].

We assessed depressive state using the K6 short screening questionnaires developed in accordance with the World Health Organization (WHO) translation guidelines [23]. The K6 consists of six items on depression and anxiety, measured on a 5-point scale (0-4). Higher scores indicate more severe depressive state. The K6 was translated into Japanese and showed good validity to DSM-IV mood and anxiety disorders in a community sample.

We measured personality traits using the Japanese version of the Ten-Item Personality Inventory (TIPI-J). TIPI-J is a measure of the Big-Five personality dimensions: extraversion, agreeableness, conscientiousness, emotional stability, and openness to experience [24]. Each item was scored at 1
TABLE 1: Characteristics of the subjects (total $N=347$ ).

\begin{tabular}{|c|c|c|c|c|}
\hline & $n(\%)$ & & & \\
\hline \multicolumn{5}{|l|}{ Work-related variables } \\
\hline \multicolumn{5}{|l|}{ Hours of work } \\
\hline Full time & $327(94)$ & & & \\
\hline Part time & $17(5)$ & & & \\
\hline \multicolumn{5}{|l|}{ Shift work } \\
\hline Rotation to nights & $266(77)$ & & & \\
\hline No rotation to nights & $12(4)$ & & & \\
\hline No shift work & $68(20)$ & & & \\
\hline \multicolumn{5}{|l|}{ Job rank } \\
\hline Manager & $18(5)$ & & & \\
\hline Middle manager & $25(7)$ & & & \\
\hline \multirow[t]{2}{*}{ Staff nurse } & $301(87)$ & & & \\
\hline & Mean & $\mathrm{SD}$ & Max. & Min. \\
\hline Age & 33.7 & 9.2 & 21 & 62 \\
\hline Overtime per week & 7.0 & 5.4 & 0 & 40 \\
\hline \multicolumn{5}{|l|}{ Job stressors } \\
\hline Quantitative job overload & 9.9 & 1.7 & 5 & 12 \\
\hline Qualitative job overload & 10.3 & 1.5 & 6 & 12 \\
\hline Physical demands & 3.3 & 0.8 & 11 & 40 \\
\hline Job control & 6.8 & 1.7 & 3 & 10 \\
\hline Skill utilization & 3.2 & 0.6 & 1 & 4 \\
\hline Interpersonal conflict & 6.3 & 1.8 & 3 & 12 \\
\hline Poor physical environment & 2.4 & 0.8 & 1 & 4 \\
\hline Suitable jobs & 2.7 & 0.7 & 1 & 4 \\
\hline Intrinsic rewards & 3.0 & 0.7 & 1 & 4 \\
\hline \multicolumn{5}{|l|}{ Psychological distress or mood } \\
\hline Vigor & 5.9 & 2.2 & 3 & 12 \\
\hline Anger, irritability & 7.2 & 2.4 & 3 & 12 \\
\hline Fatigue & 8.4 & 2.7 & 3 & 12 \\
\hline Anxiety & 7.0 & 2.6 & 3 & 12 \\
\hline Depression & 12.1 & 4.8 & 6 & 24 \\
\hline \multicolumn{5}{|l|}{ Buffering factors } \\
\hline Supervisor support & 7.4 & 2.1 & 3 & 12 \\
\hline Coworker support & 8.6 & 1.9 & 5 & 12 \\
\hline Family and friends support & 10.0 & 1.9 & 3 & 12 \\
\hline Job satisfaction and life satisfaction & 5.3 & 1.3 & 2 & 8 \\
\hline Sense of coherence & 54.2 & 11.9 & 16 & 87 \\
\hline \multicolumn{5}{|l|}{ Personality } \\
\hline Extraversion & 8.5 & 2.8 & 2 & 14 \\
\hline Agreeableness & 9.7 & 1.9 & 4 & 14 \\
\hline Conscientiousness & 7.4 & 2.4 & 2 & 14 \\
\hline Neuroticism & 8.4 & 2.5 & 2 & 14 \\
\hline Openness & 7.3 & 2.2 & 2 & 14 \\
\hline
\end{tabular}

to 7 points and the scores were totaled. It has been validated and tested for reliability in Japan by Oshio et al. [25].

We checked the distributions of each variable and some of them had nonnormal distributions. Then we used Spearman's correlation analyses to investigate potential relationships among work environment, age, job stress, SOC, personality traits, and depressive state. We examined the relationships 
TABLE 2: Spearman's correlation between depression, personality, sense of coherence, and job stress.

\begin{tabular}{|c|c|c|c|c|c|c|}
\hline & Depression & $P$ value & & SOC & $P$ value & \\
\hline Age & -0.18 & 0.00 & & 0.27 & 0.00 & \\
\hline Hours of work & -0.03 & 0.55 & n.s & 0.10 & 0.08 & n.s \\
\hline Shift work & 0.09 & 0.08 & n.s & -0.16 & 0.00 & \\
\hline Job rank & 0.05 & 0.36 & n.s & -0.14 & 0.01 & \\
\hline Overtime per week & 0.34 & 0.00 & & -0.33 & 0.00 & \\
\hline \multicolumn{7}{|l|}{ Job stressors } \\
\hline Quantitative job overload & 0.34 & 0.00 & & -0.34 & 0.00 & \\
\hline Qualitative job overload & 0.26 & 0.00 & & -0.28 & 0.00 & \\
\hline Physical demands & 0.23 & 0.00 & & -0.25 & 0.00 & \\
\hline Job control & -0.29 & 0.00 & & 0.36 & 0.00 & \\
\hline Skill utilization & -0.07 & 0.19 & n.s & 0.11 & 0.04 & \\
\hline Interpersonal conflict & 0.22 & 0.00 & & -0.28 & 0.00 & \\
\hline Poor physical environment & 0.12 & 0.03 & & -0.12 & 0.03 & \\
\hline Suitable jobs & -0.33 & 0.00 & & 0.40 & 0.00 & \\
\hline Intrinsic rewards & -0.33 & 0.00 & & 0.33 & 0.00 & \\
\hline \multicolumn{7}{|l|}{ Buffering factors } \\
\hline Supervisor support & -0.27 & 0.00 & & 0.35 & 0.00 & \\
\hline Coworker support & -0.23 & 0.00 & & 0.27 & 0.00 & \\
\hline Family and friends support & -0.13 & 0.01 & & 0.16 & 0.00 & \\
\hline Job satisfaction and life satisfaction & -0.44 & 0.00 & & 0.47 & 0.00 & \\
\hline Sense of coherence & -0.67 & 0.00 & & & & \\
\hline \multicolumn{7}{|l|}{ Personality } \\
\hline Extraversion & -0.19 & 0.00 & & 0.17 & 0.00 & \\
\hline Agreeableness & -0.19 & 0.00 & & 0.30 & 0.00 & \\
\hline Conscientiousness & -0.17 & 0.00 & & 0.27 & 0.00 & \\
\hline Neuroticism & 0.45 & 0.00 & & -0.49 & 0.00 & \\
\hline Openness & -0.16 & 0.00 & & 0.20 & 0.00 & \\
\hline
\end{tabular}

between depressive state and predictors using multiple linear regression analysis. We added variables in 3 different steps to see the influence of additional variables. We considered job stress, SOC, and personality traits as independent variables and depressive state as an explanatory variable. In Step 1, age, job stress, and work-related variables that showed a significant association with depressive state were added to the equations of depressive state. In Step 2, we added SOC scores; in Step 3, we added personality variables.

We used SPSS11 (SPSS Inc., Chicago, IL, USA) for all analyses.

\section{Results}

Characteristics of the study respondents are shown in Table 1. Completed questionnaires were returned by 386 out of 740 nurses (response rate, 52.2\%). Male nurses were excluded from the analysis due to a low sample size; only 20 of the $42(47.6 \%)$ male nurses responded. Subjects with missing values for job stress, personality inventory, and SOC were also excluded $(n=19)$. The final sample for analysis consisted of 347 female nurses (47.0\%), including managers and middle managers. Mean scores on each subscale of the questionnaire are shown in Table 1.
Age was negatively correlated with depressive state but positively related to SOC. SOC showed a relationship with shift work, job rank, and overtime hours. For almost all job stressors and personality traits, SOC and depressive state showed inverse correlation patterns. There were significant relationships between SOC and all measured personality traits; above all, neuroticism had the strongest correlation (Table 2).

Results of the multiple linear regression analyses for depressive state are shown in Table 3. Age, overtime hours per week, intrinsic rewards, job satisfaction, and life satisfaction explained $39 \%$ of the variance in depressive state. In Step 2, SOC accounted for an additional 11\% $(F=19.63, P<0.001)$ of the variance. In Step 3, personality variables accounted for an additional $3 \%(F=16.56, P<0.001)$ of the variance. Job and life satisfaction and SOC negatively related to the depressive state $(\beta=-0.76, P<0.01 ; \beta=-0.18, P<0.001$, resp.,) while neuroticism was positively correlated $(\beta=0.49$, $P<0.001)$. Also, intrinsic rewards tended to negatively relate $(\beta=-0.80, P<0.1)$. Those beta-value means that, for example, a change of $=-0.76$ units on the job and life satisfaction increase depressive state by one unit, SOC had the strong correlation with depressive state $(r=-0.67)$, but the expected collinearity did not occur in the regression model. 


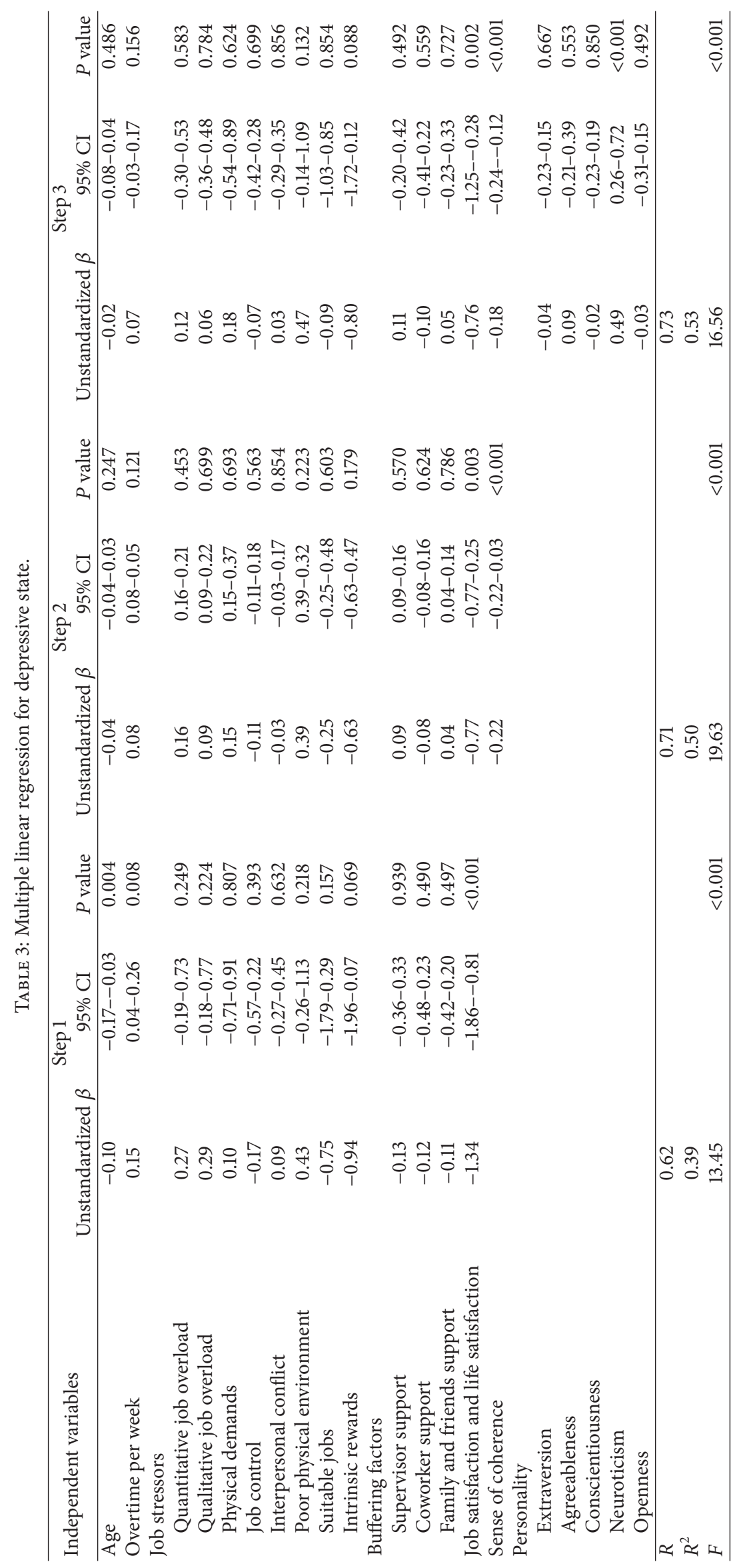




\section{Discussion}

We found that SOC, neuroticism, and job satisfaction were predictors of depressive state. Specifically, SOC was mainly associated with depressive state among female nurses.

The strength of our study is the investigation of the association among personality traits, SOC, and depressive state. To our knowledge, there was no previous study that investigated the nature and the relative strength of these relationships.

The association between SOC and depressive state was in accordance with previous studies. Malinauskiene et al. [17] indicated that weak SOC was a strong predictor of the GHQ totals among nurses in Lithuania (adjusted OR = 4.11; 95\% CI 2.24-7.56). Urakawa et al. [20] found that SOC was inversely associated with depression in Japanese factory workers $\left(\beta=-0.41 P<0.001 ; R^{2}=0.34\right)$. Among Japanese resident doctors, poorer mental health status was associated with weaker SOC scores [16]. Hospital staff members with stronger SOC may cope better with their job stress and thereby prevent the depressive state.

In our study, SOC was correlated with older age (Table 2), consistent with previous studies [12, 17, 20]. For example, Urakawa et al. [20] found that the high SOC score group were older compared with the low SOC score group. These findings support the view that SOC is not inborn or innate but is a learned capacity. Nurses with higher SOC scores are also more satisfied with their job and life (Table 2). Antonovsky [12] posited that a person with a higher SOC score would be less likely to perceive many stressful situations as threatening and anxiety provoking, whereas a person with a lower SOC score will be more vulnerable to various stressors in his or her life. Intervention support enhancing the SOC could be effective to prevent nurses from entering a depressive state.

The present study has some drawbacks. First, the sample size was a relatively small number of participants with a low response rate in only one general hospital. A longitudinal study of a larger sample is necessary. Second, we only examined work-related factors. Malinauskiene et al. [26] indicated that life-threatening events, such as divorce, family financial crisis, or death of a first-degree relative or close friend, were associated with negative subjective health among hospital nurses. Other studies found associations between life-threatening events and poor mental health and between marriage and SOC [20]. Social support from family may be important for developing SOC. In addition, characteristics of private life should be considered in evaluating general health perspectives of female employees; these nonoccupational factors should be included in the questionnaires for futures studies. Third, according to Antonovsky [12], a person with a very high score of SOC was hypothesized to present inflexibility, called "rigid SOC." However, there has been no evidence of a cutoff point indicating "rigid SOC." Potential negative effects of higher SOC score on mental health should be investigated in the future. Antonovsky [12] found that SOC was not influenced by temperament or personality traits. These contradictions, along with the current findings on the neurotic personality trait, indicate a need for future investigation of the relationships between personality traits and SOC.

\section{Conclusions}

In conclusion, SOC, neurotic personality, and job satisfaction ratings were related to the depressive state among female nurses in the Japanese general hospital. Our findings provide insight into factors associated with depressive state among nurses. From a practical perspective, the influence of SOC and neurotic personality on depressive state should be considered for health care professionals. Intervention support such as group cognitive psychotherapy to strengthen comprehensibility, manageability, and meaningfulness may help people cope better with job stress and may reduce the risk of depressive state in nurses.

\section{Conflict of Interests}

The authors declare that there is no conflict of interests regarding the publication of this paper.

\section{References}

[1] A. Bagaajav, S. Myagmarjav, K. Nanjid, S. Otgon, and Y. M. Chae, "Burnout and job stress among mongolian doctors and nurses," Industrial Health, vol. 49, no. 5, pp. 582-588, 2011.

[2] V. Bonneterre, S. Liaudy, G. Chatellier, T. Lang, and R. de Gaudemaris, "Reliability, validity, and health issues arising from questionnaires used to measure psychosocial and organizational work factors (POWFs) among hospital nurses: a critical review," Journal of Nursing Measurement, vol. 16, no. 3, pp. 207230, 2008.

[3] R. H. Griep, L. Rotenberg, A. G. Vasconcellos, P. Landsbergis, C. M. Comaru, and M. G. Alves, "The psychometric properties of demand-control and effort-reward imbalance scales among Brazilian nurses," International Archives of Occupational and Environmental Health, vol. 82, no. 10, pp. 1163-1172, 2009.

[4] A. Jolivet, S. Caroly, V. Ehlinger et al., "Linking hospital workers' organisational work environment to depressive symptoms: a mediating effect of effort-reward imbalance? The ORSOSA study," Social Science and Medicine, vol. 71, no. 3, pp. 534-540, 2010.

[5] D. Jurado, M. Gurpegui, O. Moreno, M. C. Fernández, J. D. Luna, and R. Gálvez, "Association of personality and work conditions with depressive symptoms," European Psychiatry, vol. 20, no. 3, pp. 213-222, 2005.

[6] Y. Kikuchi, M. Nakaya, M. Ikeda, K. Narita, M. Takeda, and M. Nishi, "Effort-reward imbalance and depressive state in nurses," Occupational Medicine, vol. 60, no. 3, pp. 231-233, 2010.

[7] M. Schulz, A. Damkröger, C. Heins et al., "Effort-reward imbalance and burnout among German nurses in medical compared with psychiatric hospital settings," Journal of Psychiatric and Mental Health Nursing, vol. 16, no. 3, pp. 225-233, 2009.

[8] M. Schulz, A. Damkröger, E. Voltmer et al., "Work-related behaviour and experience pattern in nurses: impact on physical and mental health," Journal of Psychiatric and Mental Health Nursing, vol. 18, no. 5, pp. 411-417, 2011.

[9] S. Stansfeld and B. Candy, "Psychosocial work environment and mental health - a meta-analytic review," Scandinavian Journal 
of Work, Environment and Health, vol. 32, no. 6, pp. 443-462, 2006.

[10] O. J. Bienvenu, J. F. Samuels, P. T. Costa, I. M. Reti, W. W. Eaton, and G. Nestadt, "Anxiety and depressive disorders and the five-factor model of personality: a higher- and lowerorder personality trait investigation in a community sample," Depression and Anxiety, vol. 20, no. 2, pp. 92-97, 2004.

[11] Y. Kikuchi, M. Nakaya, M. Ikeda, M. Takeda, and M. Nishi, "Job stress and temperaments in female nurses," Occupational Medicine, vol. 63, no. 2, pp. 123-128, 2013.

[12] A. Antonovsky, Unraveling the Mystery of Health, How People Manage Stress and Stay Well, Jossey-Bassey Publishers, San Francisco, Calif, USA, 1987, Translated into Japanese by Y. Yamazaki and K. Yoshi, Tokyo, Japan, 2001.

[13] A. Antonovsky, Health, Stress, and Coping-New perspective on Mental and Physical Well-Being, Jossey Bass, San Francisco, Calif, USA, 1979.

[14] A. Antonovsky, "The salutogenic model as a theory to guide health promotion 1," Health Promotion International, vol. 11, no. 1, pp. 11-18, 1996.

[15] B. Buddeberg-Fischer, M. Stamm, C. Buddeberg, and R. Klaghofer, "Chronic stress experience in young physicians: impact of person- and workplace-related factors," International Archives of Occupational and Environmental Health, vol. 83, no. 4, pp. 373-379, 2010.

[16] T. Haoka, S. Sasahara, Y. Tomotsune, S. Yoshino, T. Maeno, and I. Matsuzaki, "The effect of stress-related factors on mental health status among resident doctors in Japan," Medical Education, vol. 44, no. 8, pp. 826-834, 2010.

[17] V. Malinauskiene, P. Leišyte, and R. Malinauskas, "Psychosocial job characteristics, social support, and sense of coherence as determinants of mental health among nurses," Medicina, vol. 45, no. 11, pp. 910-917, 2009.

[18] N. Ogińska-Bulik, "The role of personal and social resources in preventing adverse health outcomes in employees of uniformed professions," International Journal of Occupational Medicine and Environmental Health, vol. 18, no. 3, pp. 233-240, 2005.

[19] K. Urakawa and K. Yokoyama, "Sense of coherence (SOC) may reduce the effects of occupational stress on mental health status among Japanese factory workers," Industrial Health, vol. 47, no. 5, pp. 503-508, 2009.

[20] K. Urakawa, K. Yokoyama, and H. Itoh, "Sense of coherence is associated with reduced psychological responses to job stressors among Japanese factory workers," BMC Research Notes, vol. 5, article 247, 2012.

[21] T. Shimomitsu, K. Yokoyama, H. Ohno, T. Maruta, and T. Tanigawa, "Manual of the brief job stress questionnaire," in Reports on the Study of Job Stress and Its Effects on Health in the Workplace: The Research Grant for the Prevention of Workrelated Diseases from the Japan Ministry of Labor, pp. 17-27, The Ministry of Labor, Tokyo, Japan, 2000, (Japanese).

[22] T. Feldt, H. Lintula, S. Suominen, M. Koskenvuo, J. Vahtera, and M. Kivimäki, "Structural validity and temporal stability of the 13-item sense of coherence scale: prospective evidence from the population-based HeSSup study," Quality of Life Research, vol. 16, no. 3, pp. 483-493, 2007.

[23] T. A. Furukawa, N. Kawakami, M. Saitoh et al., "The performance of the Japanese version of the K6 and K10 in the World Mental Health Survey Japan," International Journal of Methods in Psychiatric Research, vol. 17, no. 3, pp. 152-158, 2008.
[24] S. D. Gosling, P. J. Rentfrow, and W. B. Swann Jr., "A very brief measure of the Big-Five personality domains," Journal of Research in Personality, vol. 37, no. 6, pp. 504-528, 2003.

[25] A. Oshio, S. Abe, and P. Cutrone, "Development, reliability, and validity of the Japanese version of Ten Item Personality Inventory (TIPI-J)," The Japanese Journal of Personality, vol. 21, no. 1, pp. 40-52, 2012.

[26] V. Malinauskiene, P. Leisyte, M. Romualdas, and K. Kirtiklyte, "Associations between self-rated health and psychosocial conditions, lifestyle factors and health resources among hospital nurses in Lithuania," Journal of Advanced Nursing, vol. 67, no. 11, pp. 2383-2393, 2011. 


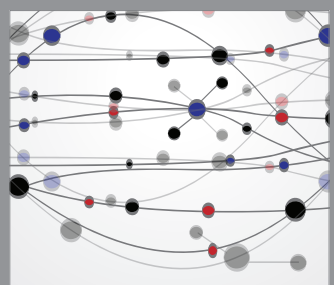

The Scientific World Journal
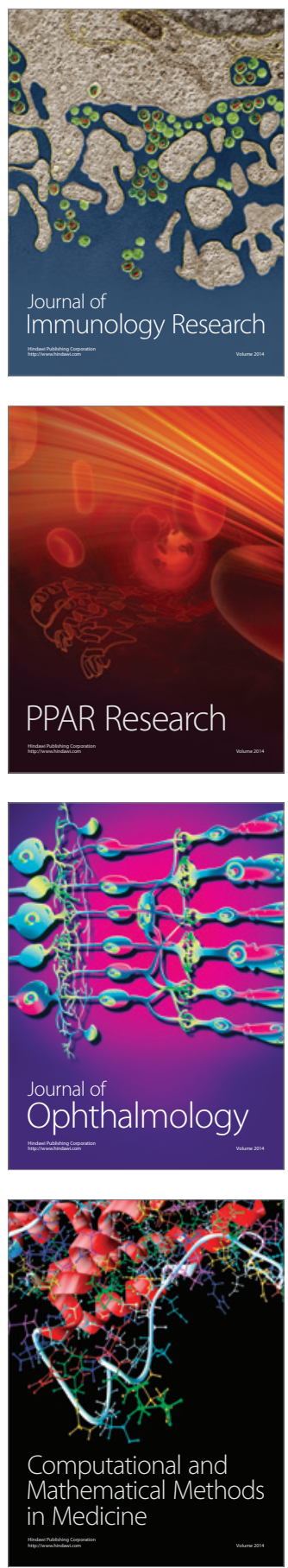

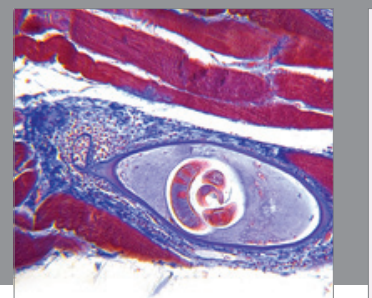

Gastroenterology

Research and Practice
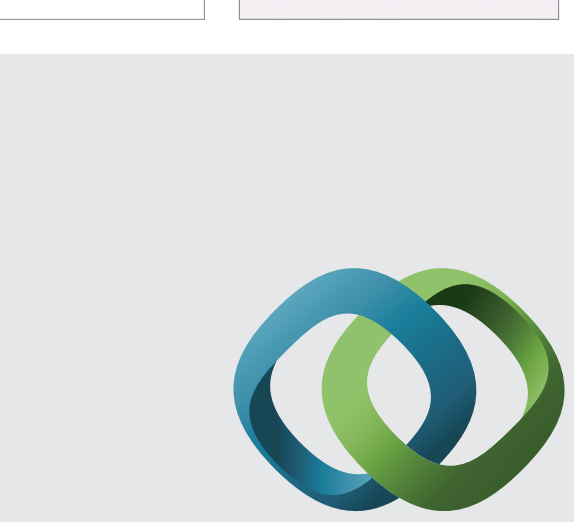

\section{Hindawi}

Submit your manuscripts at

http://www.hindawi.com
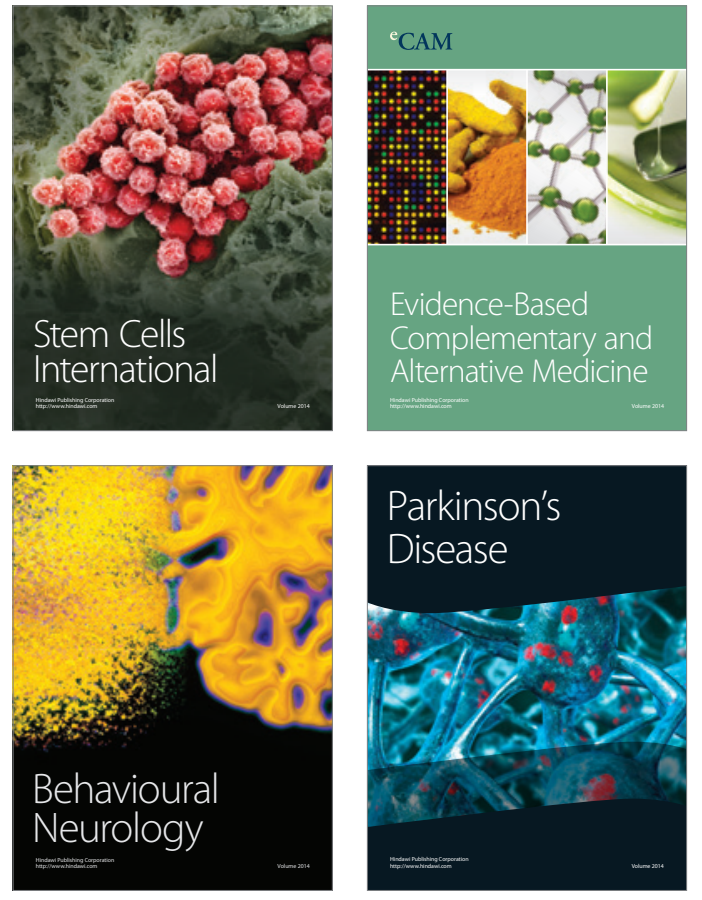
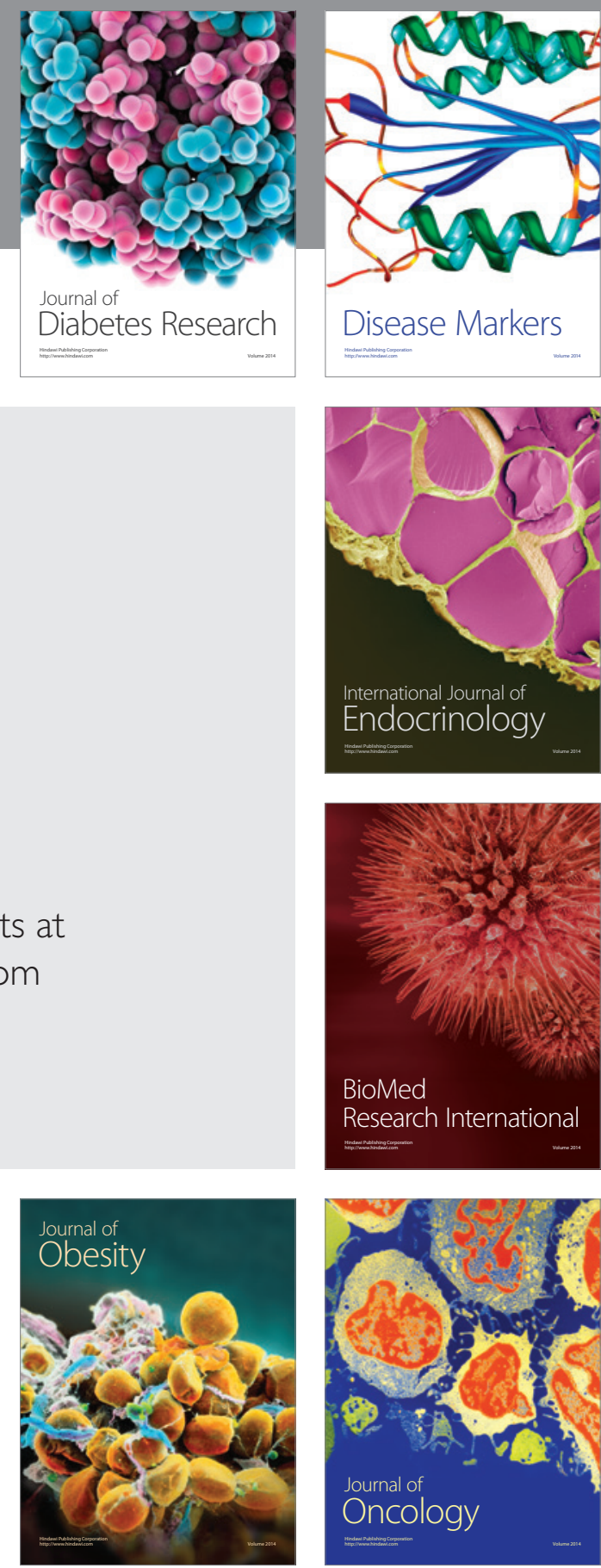

Disease Markers
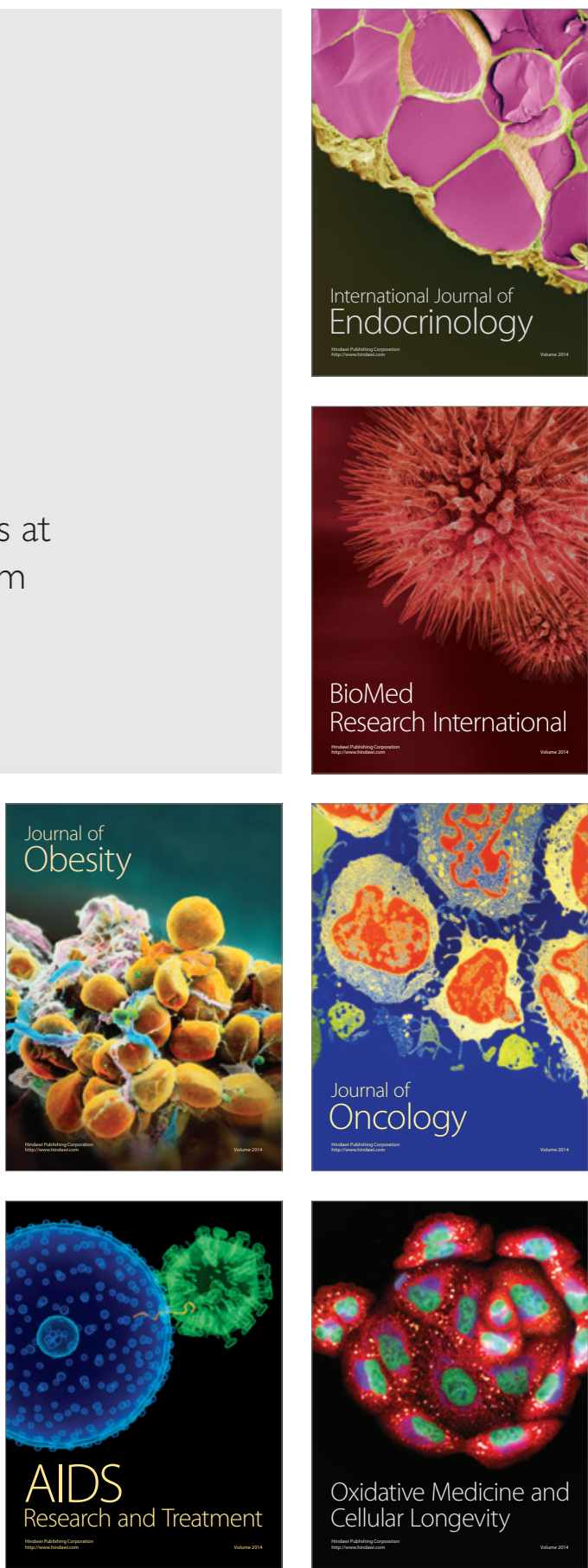